\title{
COMPARISON STUDY OF SECURITY FEATURES IN OSN
}

\author{
Shelma Joseph.M1, Niyas Narimukkil ${ }^{2}$ \\ ${ }^{1}$ Student Member, Department of Computer Science, KMCT CE, Kerala, India \\ ${ }^{2}$ Assistant Professor, Department of Computer Science, KMCT CE, Kerala, India
}

\begin{abstract}
An OSN user has lot of concern about their own privacy. Any user who is a active participant of any online social media network has a very important part of educating themselves and their near ones about the way security and privacy settings are configured. Though OSN is there for lot of things like getting connected to people, posting our views, photos and videos but it is also a hub for hackers and scammers and makes things worse for others. The goal of this paper is to make a comparative study about the different security features that is there in OSN.We are discussing from the initial stages of an OSN and explain how a user can decide about his privacy and security features.
\end{abstract}

Keywords: Facebook, Security, Photo, Photo Sharing, Tagging

\section{INTRODUCTION}

Online social network has become a very important part of day to day life and has completely changed the way we share information, the way we have social communication and the way we talk to each other. In today's world most of the people just don't think about anything before posting anything on a social media network. Once we post a photo or a video that makes a permanent record in the internet which can be used for lot of unwanted things that we would have never imagined or expected. This can be explained with a example too is a celebrity, $\mathrm{Y}$ posts a photo with $\mathrm{X}$ which will reveal their friendship to the whole world and create issues for X.The situation becomes even more bad when photo tagging and sharing comes into the picture.

To get more people involved in the activities of a social networking site. Online social networks like face book encourages users to post photos as well as tag those people who are there in this photo and other friends. The photos that are shared doesn't have any rules too. So coming to the main concern, when we share and tag the photo what if one person in the photo or more than one person in the photo are not willing to share their photo. What if the person think he also should have rights while his photo is shared .To address this issue we need to have a clear study about the privacy issues in and over OSN .Privacy is a moving away from from a social network. As Altman says about privacy regulation theory [1][2] "privacy is a dynamic and dialectic boundary regulation process where privacy is not static but "a way a person becomes selective in control of access to the self or to ones group". Dialectic means closeness and openness of a person to others and the word "dynamic" refers to desired level of privacy keeps changing with time respect to the environment.

Actually during the process of regulating the privacy, we try to match the achieved privacy level to the one we desire. At the starting level of privacy, we can experience the confidence we desire when we don't want to show and when we want to enjoy the attention we desired that we wish to show everybody. Concluding the statement, if the actual privacy level is more than the desire level then we will feel left alone or isolated; on the other side if the actual privacy level is smaller than the desired level we will feel vulnerable or over exposed.

\subsection{Posting Photos-Without Privacy}

When we consider posting the photos in OSN in the initial days, we didn't have any option to select the privacy .All photos were visible to every on and anybody could access our photos. While resulted in lot of misuse of photos. This misuse of photo lead to lot of problems. There was always a fear of posting our own photos. This lead to people posting fake pictures such as dolls, flowers or any other relevant photos.

\subsection{Posting Photos-Privacy Options}

Users in an OSN share a lot of information like photos, their views, videos, long messages but the importance of privacy implications of doing so has yet to come .We understood from the previous topic how bad it is when we don't have any privacy in our online social network. There are three factors that discuss on privacy, they are1.A online social network user reveals too much information;2. A social networking site doesn't take too many steps to protect user privacy; 3.There is so many people outside waiting to get user information to make use of it in a wrong manner.That's when a online social networking site like face book came with flexibility in privacy option, which was considered to be a good deal.

The user settings option of privacy in their own social networking page allows a user to decide and specify the people to whom they can be visible during searches, which will allow them to see their profile, to get their contact details and their photos. Adding to that privacy option, there is also a block option to block few users whom we feel are unnecessary. As per the usage agreement, a specific OSN user can request OSN not to share any of their information 


\subsection{Posting Photos -Tagging Options}

What is tagging? It is a method of pointing your friends or anyone else the photos that you post on a online social network This tagging creates a link that anybody can follow and get information about who all there in that photo. What can a tag do? It add people in the photo, give them information about that photo, help them follow the other posts about that photo and help them receive notifications ,involve people in sharing information about that photo. You can tag any photo and add details to it. If you are not interested in any tagging, we can untag that with following options

\subsubsection{From your Time Line: Removal}

A time line on a OSN says who you are,so the unimportant things regarding you that you don't like to have on your wall can be removed by the following ways

\subsubsection{Tag Removal or Reporting the Post}

You can easily do the following:

a. Tag Removal. It won be on your wall but on the friends wall who posted it.

b. Send a message-To the owner: Mention the reason and send a message to the owner

c. To Face book -Send a report. :Report its abusive and sooner it will be removed

d.Block-The owner of the post: the person who was blocked cannot see your post

\subsection{Posting Photos -With Security Questions}

On most current OSN, , a user is not in a position to decide what appears outside the page. In [3], Thomas, Grier and Nicol examine how joint privacy is less and if we don't control we can inadvertently reveal sensitive information about a user. To remove this threat, they suggest OSN's privacy model to be adapted to achieve every body's privacy. Specifically, there should be a mutually acceptable privacy policy determining which information should be posted and shared For example, people showing up together on a photo can be posted on the wall, but if there is one person who is not willing the to post but has no other option other than un tagging himself. The problem doesn't stop there, he/she can hide the post only from their page but the photo will appear on other's wall.

Posting photos with security questions sends a same time to all the people found on the photo, only when all accept to post the photo the photo comes on the wall. This method will minimize the number of un wanted photos being uploaded.

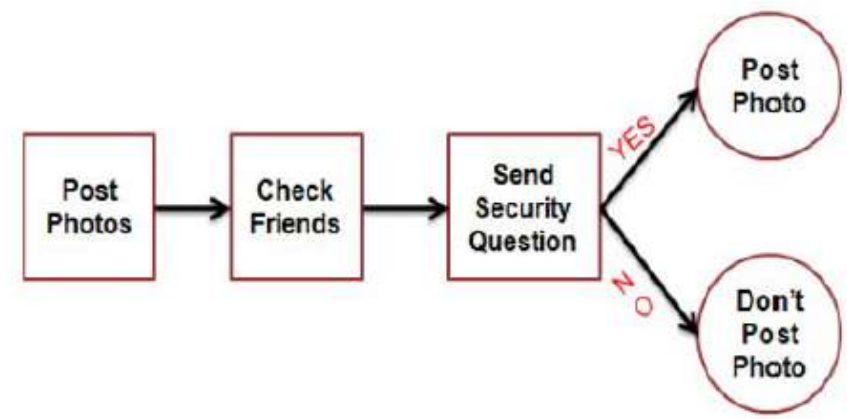

Fig. 1: Architecture of Posting Photo with security questions

\subsection{Posting Photos -Automatic Analysis}

Posting photos with security questions sends a same time to all the people found on the photo, only when all accept to post the photo the photo comes on the wall. This method will minimize the number of un wanted photos being uploaded but increase the waiting time for the photos to be posted.

To eradicate this problem we develop a automatic analysis ,where the system will ask the user every time when the person says "No " when the security question is asked .This analysis will have few questions with Boolean values(yes, no) as answers. Based on the answer the we predict the next time we post a photo and decide whether the photo has to be posted or not. This approach will reduce the waiting time in the future and avoid unnecessary same time questions send to all users in the photo.

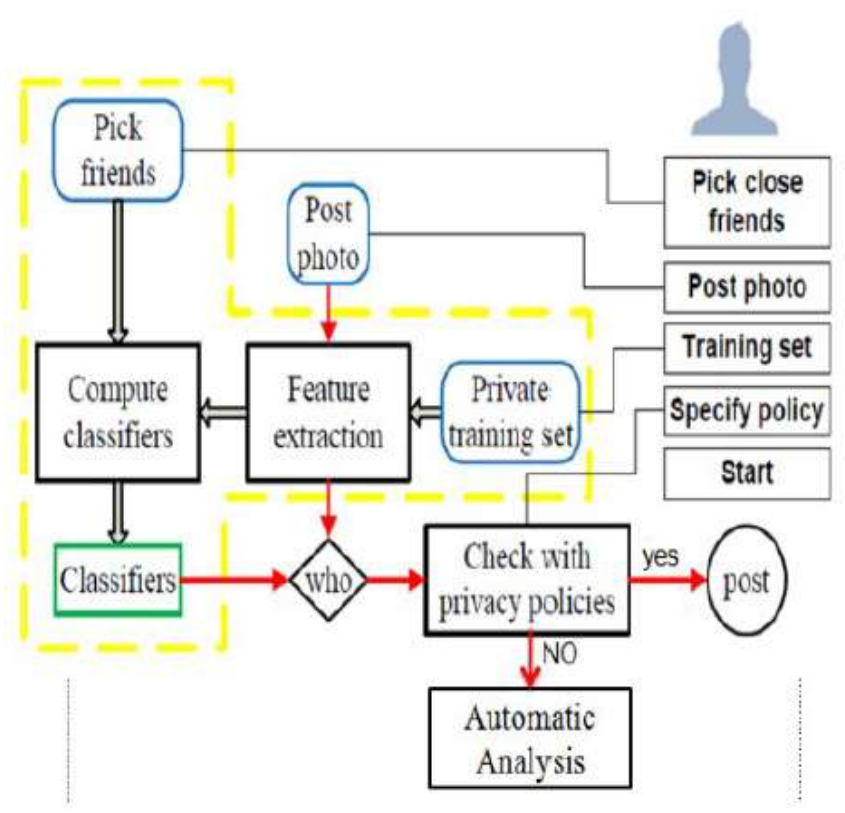

Fig. 2: Architecture of Posting Photo with automatic Analysis 
Table -1: Comparison of different security features

\begin{tabular}{|c|c|c|c|}
\hline Feature & Methodology & Advantage & $\begin{array}{l}\text { Disadvanta } \\
\text { ge }\end{array}$ \\
\hline No Privacy & $\begin{array}{l}\text { Photos has no } \\
\text { privacy }\end{array}$ & $\begin{array}{l}\text { No } \\
\text { restriction }\end{array}$ & $\begin{array}{l}\text { Un wanted } \\
\text { usage of } \\
\text { photos }\end{array}$ \\
\hline $\begin{array}{l}\text { With } \\
\text { Privacy }\end{array}$ & $\begin{array}{l}\text { Photos have } \\
\text { privacy } \\
\text { measures }\end{array}$ & $\begin{array}{l}\text { Photos are } \\
\text { secure }\end{array}$ & $\begin{array}{l}\text { Limited } \\
\text { users can } \\
\text { view photos }\end{array}$ \\
\hline $\begin{array}{l}\text { With } \\
\text { Tagging }\end{array}$ & $\begin{array}{l}\text { Photos with } \\
\text { tagging and } \\
\text { editing options }\end{array}$ & $\begin{array}{l}\text { Photos are } \\
\text { secure and } \\
\text { will be } \\
\text { available } \\
\text { on their } \\
\text { wall. }\end{array}$ & $\begin{array}{l}\text { Photos will } \\
\text { be available } \\
\text { on others } \\
\text { wall even if } \\
\text { it removed } \\
\text { from theirs }\end{array}$ \\
\hline $\begin{array}{l}\text { With } \\
\text { Security } \\
\text { questions }\end{array}$ & $\begin{array}{l}\text { Photos posted } \\
\text { only after the } \\
\text { questions are } \\
\text { answered "yes" }\end{array}$ & $\begin{array}{l}\text { Photos will } \\
\text { be posted } \\
\text { only if all } \\
\text { the people } \\
\text { in the photo } \\
\text { give } \\
\text { permission. } \\
\text { High } \\
\text { security } \\
\text { and } \\
\text { privacy. }\end{array}$ & $\begin{array}{l}\text { Questions } \\
\text { will be asked } \\
\text { recurrently }\end{array}$ \\
\hline $\begin{array}{l}\text { Automatic } \\
\text { Analysis }\end{array}$ & $\begin{array}{l}\text { Analysis based } \\
\text { on the answers } \\
\text { for the question } \\
\text { is done }\end{array}$ & $\begin{array}{l}\text { 1.No } \\
\text { recurrent } \\
\text { questions. } \\
2 . \text { High } \\
\text { privacy and } \\
\text { security }\end{array}$ & $\begin{array}{l}\text { Many photos } \\
\text { might go } \\
\text { without } \\
\text { uploading }\end{array}$ \\
\hline
\end{tabular}

\section{CONCLUSION}

Sharing a photo or video is a most common and popular feature in a online social network, But the saddest part is that a small care less post of a photo may bring out lot of private details about any individual .To eradicate this privacy leakage a method of asking security questions was implemented which will ask every individuals permission to post a photo. But this method will lead to too many questions and time consumption Hence we propose a system with automatic analysis which will reduce the questions in the future and reduce the amount of time. This system is designed for high privacy and security.

\section{ACKNOWLEDGEMENT}

I take this opportunity to that my family members and my class mates for their support and also my guide Mr.Niyas N. for his valuable time and suggestions

\section{REFERENCES}

[1]. I. Altman. Privacy regulation: Culturally universal or culturally specific? Journal of Social Issues, 33(3):66-84, 1977
[2]. L. Palen. Unpacking privacy for a networked world. pages 129 to 136. Press, 2003.

[3]. K. Thomas, C. Grier, and D. M. Nicol. Unfriendly: Multi-party privacy risks in social networks. In M. J. Atallah and N. J. Hopper, editors, Privacy Enhancing Technologies, volume 6205 of Lecture Notes in Computer Science, pages 236-252. Springer, 2010

[4]. Kaihe Xu, Student Member, IEEE, Yuanxiong Guo, Member, IEEE, Linke Guo, Member, IEEE, Yuguang Fang, Fellow, IEEE,Xiaolin Li, Member,IEEE.My Privacy MyDecision Control of photo sharing on OSN10.1109/TDSC.2015.2443795 IEEE Transaction

\section{BIOGRAPHIES}

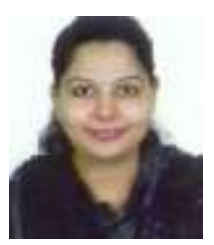

Perusing $\mathrm{M}$ tech in KMCT college of Engineering. Worked in IT for two years and as a lecturer for 2 years

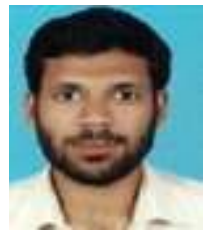

Asst Professor of Computer Science Department in KMCT college of Engineering 